\title{
Noninvasive Oxygen Therapies in Oncologic Patients
}

\author{
Michael C. Sklar, Bruno L. Ferreyro, and Laveena Munshi
}

\section{Contents}

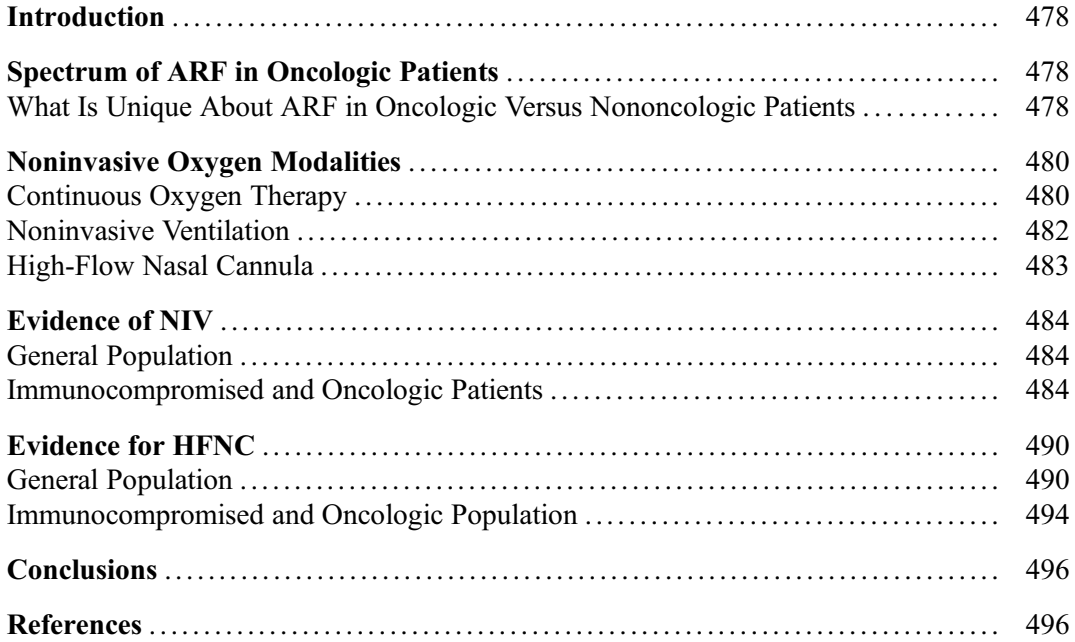

\section{Abstract}

Acute hypoxemic respiratory failure (ARF) is the most common cause of critical illness in oncologic patients. Despite significant advancements in survival of oncologic patients who develop critical illness, mortality rates in those requiring invasive mechanical

M. C. Sklar · B. L. Ferreyro · L. Munshi $(\bowtie)$

Interdepartmental Division of Critical Care Medicine,

Mount Sinai Hospital, Sinai Health System, University of

Toronto, Toronto, ON, Canada

e-mail: michaelcsklar@gmail.com;

bruno.ferreyro@uhn.ca;

Laveena.Munshi@sinaihealthsystem.ca ventilation have improved but remain high. Avoiding intubation is paramount to the management of oncologic patients with ARF. There are important differences between the oncologic patient with ARF compared to the general ICU population that likely underlie the increased mortality once intubated. Noninvasive oxygen modalities have been recognized as an important therapeutic approach to prevent intubation. Continuous low-flow oxygen therapy, noninvasive ventilation, and highflow nasal cannula are the most commonly used noninvasive oxygen therapies in recent years. They have unique physiologic 
properties. The data surrounding their efficacy in the general ICU population and oncologic population has evolved over time reflecting the changes in the oncologic population. This chapter reviews the three different noninvasive oxygen modalities, their physiologic impact, and evidence surrounding their effectiveness.

\section{Keywords}

High-flow nasal cannula $\cdot$ High-flow oxygen therapy $\cdot$ Low-flow oxygen therapy ·

Continuous oxygen therapy $\cdot$ Noninvasive ventilation $\cdot$ Acute respiratory failure $\cdot$ Acute respiratory distress syndrome $\cdot$ Oncologic critical care $\cdot$ Immunocompromised

\section{Introduction}

Acute hypoxemic respiratory failure (ARF) is the most common cause of critical illness in oncologic patients [1-3]. Avoiding intubation is paramount to the management of oncologic patients with ARF. The risks associated with intubation are pronounced in the immunocompromised and oncologic population. These risks include numerous infectious, musculoskeletal, respiratory, and neurologic complications. Oncologic patients may present with a greater frequency of frailty at the time of critical illness, a higher likelihood of succumbing to aggressive or drug-resistant pathogens or they may experience a blunted or dysregulated host response [4-6]. As such, patients who progress to require invasive mechanical ventilation are subject to increased mortality compared to the general ICU population [7].

In hypoxemic oncologic patients, noninvasive oxygen therapy may be delivered via simple face mask (continuous oxygen therapy (COT)), noninvasive ventilation (NIV), or high-flow nasal cannula (HFNC). Earlier studies in immunocompromised patients receiving NIV compared to COT suggested a reduced need for intubation $[6,8]$. This resulted in adoption of NIV as a noninvasive strategy to support oncologic patients in an attempt to prevent intubation. However, these results have been called into question in recent years [9]. Furthermore, we have recently seen the development of HFNC with promising preliminary results across the general ICU population. It is unclear whether these promising results with HFNC translate to the oncologic population. With the goal to reserve intubation in those failing noninvasive oxygenation strategies, there remains a need to better understand these therapies in this unique population.

This chapter will focus on the rationale for preventing intubation in the oncologic population, the mechanisms of the various noninvasive oxygen modalities, evidence-to-date of these modalities across the general and oncologic patients, and future areas of consideration.

Spectrum of ARF in Oncologic Patients

The number of living patients with cancer has been increasing steadily over the last several years [10]. The spectrum of ARF in oncologic patients varies widely and may be induced by the underlying malignancy or be secondary to treatment-associated toxicities (Fig. 1).

\section{What Is Unique About ARF in Oncologic Versus Nononcologic Patients}

While mortality across critically ill oncologic patients has decreased significantly in recent decades with advancements in oncologic and critical care, mortality across ARF and acute respiratory distress syndrome (ARDS) remains high [11]. There are a series of factors that are theorized to be underlying this increased mortality. A thorough understanding of these factors is necessary when considering which noninvasive oxygen strategy one may choose.

\section{Cause of ARF}

ARF in the oncologic patient can broadly be categorized into disease-associated ARF and treatment-associated ARF. Disease associated causes of respiratory failure include tumor infiltration into the airway, pulmonary leukostasis, leukemic infiltrates, and malignant pleural effusions among others. Treatment-associated 


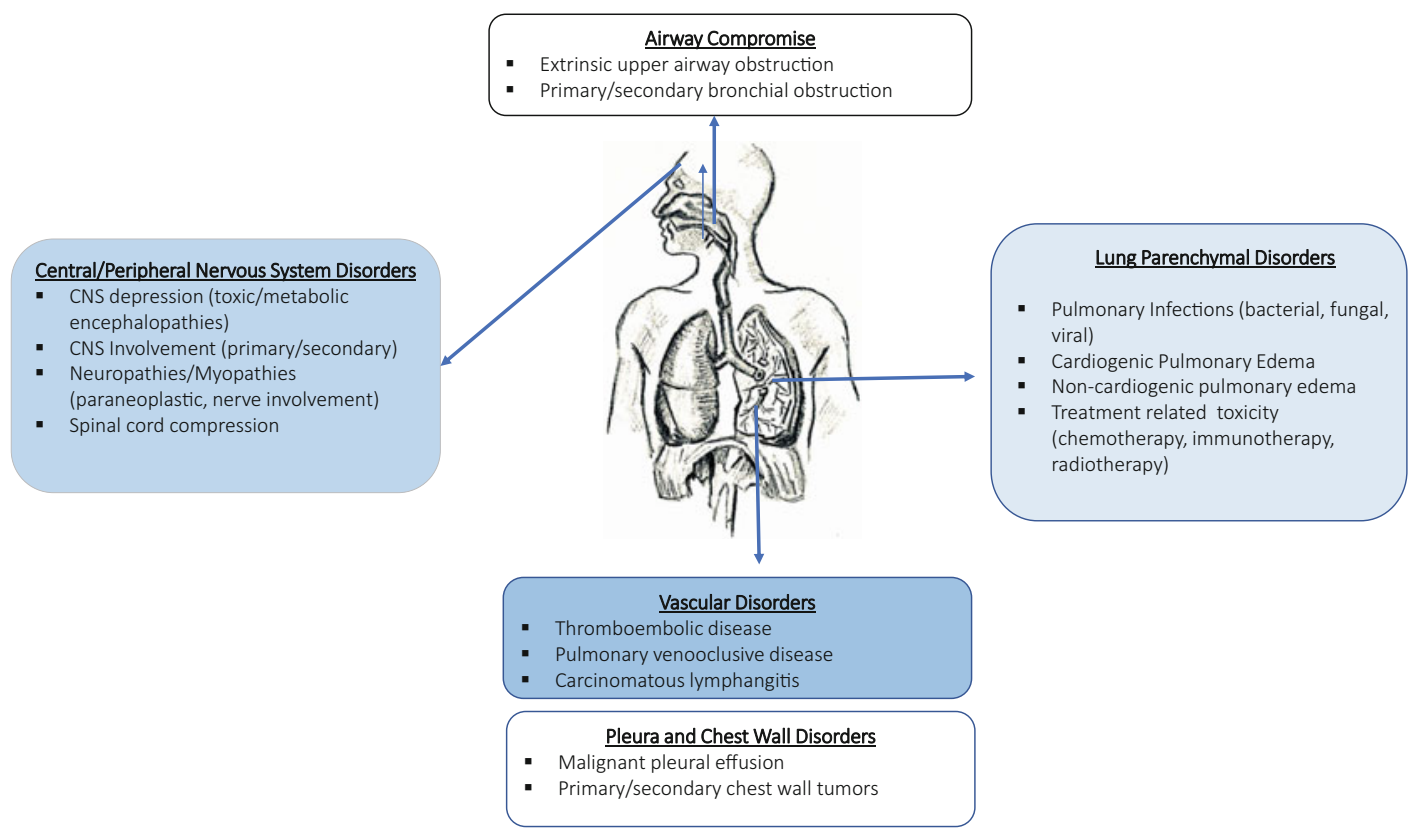

Fig. 1 Causes of acute respiratory failure across oncologic patients

toxicities may occur early during treatment (tumor lysis syndrome, cytokine release syndrome, all-transretinoic acid differentiation syndrome), at the height of treatment effect (neutropenicassociated infectious complications), during recovery (neutrophil reconstitution or engraftment syndrome associated with ARDS), or as a late toxicity (cardiomyopathy, pulmonary pneumonitis). These causes are unique to the oncologic population. While infectious etiologies remain the most common culprit, a higher proportion of noninfectious causes are noted in this population. Therefore, an accurate understanding of the differential is imperative to guide early recognition, anticipation of deterioration, and institution of appropriate supportive care and treatment. Recognizing and projecting the reversibility of the underlying cause is an important factor in deciding on the noninvasive or invasive modality one may choose as first line.

\section{Diagnostic Challenge}

Undiagnosed ARF is associated with a high mortality [12]. Given this, meticulous attention over previous decades has been dedicated to the optimal approach to diagnostic evaluation of pulmonary infiltrates and ARF in the oncologic population. Diagnostic workup often includes, a series of noninvasive serum and sputum microbiologic tests (sputum cultures, induced sputum for pneumoncystic jirovecii pneumonia, cytomegalovirus serum evaluation, serum galactomannan, nasopharyngeal swab for viral polymerase chain reaction, etc.), imaging modalities (CT thorax, echocardiography if hydrostatic pulmonary edema is considered), and possible fiberoptic bronchoscopy for further microbiologic evaluation if no diagnosis has been yielded. This investigative workup is often more invasive and requires more imaging and transportation for the oncologic population compared to the general ICU population.

\section{Frailty}

Oncology patients represent a subgroup particularly susceptible to frailty. During intensive treatments, patients may be exposed to transient illnesses, hospitalizations, interruption in normal nutrition regimens, steroids, limited mobility due to toxic side effects, and recovery from surgery. All of these factors potentially put them at higher risk of developing frailty, particularly precritical 
illness. Frailty is increasingly being recognized as an important determinant of duration of mechanical ventilation, ICU survival and ICU functional recovery [13-15]. In this population, significant loss of muscle mass that may occur during treatment puts them at higher risk of frailty or prolonged mechanical ventilation due to the development of diaphragmatic dysfunction in the setting of ARF.

\section{Increased Mortality}

Over the last decade, there has been consistent evidence suggesting that oncologic patients with ARF who undergo invasive mechanical ventilation face a significantly increased risk of poor survival and functional outcomes [2, 16]. Although this association might be explained partially by indication bias, making it challenging to confirm a true causal effect, it is widely accepted that the initial oxygen delivery strategy is a key factor while approaching the management of ARF in this vulnerable population. Mortality across oncologic patients who require invasive mechanical ventilation can range from $40 \%$ to $50 \%$ and can reach as high as $80 \%$ in a certain subset of oncologic patients (i.e., allogenenic hematopoietic stem cell transplant patients, invasive fungal infections) [2, 17]. Risk factors for mortality are outlined in Table 2.

\section{Long-Term Outcomes Trajectory}

Despite evidence of a high mortality in the face of ARF, there is a paucity of data on the long-term outcomes of oncologic patients with ARF. What is unique about this population compared to the general population of ARDS survivors is that they have a potentially reversible underlying comorbid condition, and therefore their functional recovery and diseased trajectory could follow a different path. More data is needed to further delineate this dedicated to this population $[11,18]$.

\section{Hematologic Malignancy Versus Solid Tumor}

Outcomes of oncologic patients who develop critical illness have improved over the years with reports mirroring, in some studies, mortality rates across the general ICU populations. Critical illness is often associated with a higher severity of illness and, as a result, higher mortality [19, 20]. The more profound and prolonged nature of the immunocompromised state that is achieved, as a consequence of intensive curative therapies, render this vulnerable population to a greater risk of bacterial, viral, and invasive fungal infections. Noninfectious etiologies unique to the hematologic malignancy population include pulmonary leukostasis, pulmonary leukemic infiltrates, lung alveolar proteinosis in the setting of tumor lysis syndrome, alveolar hemorrhage, differentiation syndrome and capillary leak as a subset of treatment-associated toxicities, cytokine release syndrome-inducing ARDS, immune reconstitution-associated ARDS in the setting of neutrophil recovery, and radiation-associated pneumonitis [21]. In the allogeneic hematopoietic stem cell transplant, additional causes include engraftment syndrome, diffused alveolar hemorrhage, idiopathic pneumonia syndrome, and acute/chronic graft versus host disease [22, 23].

\section{Noninvasive Oxygen Modalities}

Noninvasive oxygenation strategies in the oncologic patient can be delivered by conventional face-mask oxygen therapy (COT), noninvasive ventilation (NIV), and high-flow nasal oxygen cannula therapy (HFNC). Each of these techniques have unique physiological considerations and important advantages and disadvantages that must be understood so that a clinician can deliver safe, effective, and personalized therapy to this high-risk patient population (Table 1). The following section will discuss the basic physiologic principles, advantages, and possible disadvantages of each.

\section{Continuous Oxygen Therapy}

Oxygen delivered to spontaneously breathing patients is most commonly delivered by masks. Broadly speaking, oxygen can be delivered by simple, partial rebreathing and non-rebreathing masks. Flow rates range from $6 \mathrm{~L} / \mathrm{min}$ (simple) to $15 \mathrm{~L} / \mathrm{min}$ (non-rebreather) with a fraction of 
Table 1 Benefits and pitfalls of noninvasive oxygen modalities

\begin{tabular}{|c|c|c|}
\hline & Benefits & Pitfalls \\
\hline $\begin{array}{l}\text { Continuous } \\
\text { low-flow } \\
\text { oxygen therapy }\end{array}$ & $\begin{array}{l}\text { Comfortable } \\
\text { Ease of application } \\
\text { Amenable for transportation } \\
\text { Does not impair cough/secretion } \\
\text { management }\end{array}$ & $\begin{array}{l}\text { In patients with high work of breathing, they may } \\
\text { entrain a high volume of room air dissolving the } \\
\text { delivered alveolar oxygen content } \\
\text { Local toxic effects of high inspired } \mathrm{FiO}_{2}\end{array}$ \\
\hline $\begin{array}{l}\text { Noninvasive } \\
\text { ventilation }\end{array}$ & $\begin{array}{l}\text { Continuous PEEP to facilitate recruitment } \\
\text { Inspiratory positive pressure to support tidal } \\
\text { volumes during poor compliance or fatigue } \\
\text { Recruitment and decrease work of breathing } \\
\text { may facilitate a decreased in } \mathrm{FiO}_{2} \\
\text { requirements } \\
\text { Decrease in preload/afterload in the setting } \\
\text { of a cardiogenic pulmonary edema } \\
\text { Amenable for transportation }\end{array}$ & $\begin{array}{l}\text { Decrease in preload or increase in right ventricular } \\
\text { afterload could precipitate or exacerbate shock } \\
\text { Secretion clearance challenging with face mask } \\
\text { interface } \\
\text { Potential for injurious ventilation particularly in } \\
\text { the setting of a high work of breathing } \\
\text { May delay or impair administration of evidence- } \\
\text { based ICU therapies or workup (nutrition, } \\
\text { mobility, imaging, bronchoscopy) } \\
\text { Facemask interface uncomfortable by some }\end{array}$ \\
\hline $\begin{array}{l}\text { High-flow nasal } \\
\text { cannula }\end{array}$ & $\begin{array}{l}\text { Comfortable } \\
\text { Heated and humidified oxygen enhances } \\
\text { mucociliary clearance } \\
\text { Possible generation of PEEP to facilitate } \\
\text { recruitment } \\
\text { High flows help prevent entrainment of } \\
\text { room air thus minimizing dilution of } \\
\text { administered oxygen } \\
\text { Deadspace washout may contribute to } \\
\text { decreasing work of breathing } \\
\text { Can facilitate fiberoptic bronchoscopy }\end{array}$ & $\begin{array}{l}\text { Cannot transport } \\
\text { Uncertainty surrounding levels of generated PEEP } \\
\text { based upon patient features } \\
\text { Highest flows may be considered uncomfortable } \\
\text { by some }\end{array}$ \\
\hline
\end{tabular}

PEEP positive end expiratory pressure

inspired oxygen $\left(\mathrm{FiO}_{2}\right)$ of approximately $30-90 \%$ [24]. The advantages to COT is its noninvasive nature and its portability.

One of the major limitations of conventional face-mask oxygen delivery systems is the limited inspiratory flow rate it can deliver. In the setting of respiratory distress, the inspiratory flow rate of dyspneic patients often greatly exceeds the upper limit of flow rates delivered by these conventional systems and a significant entrainment of ambient air limits the delivery of the targeted $\mathrm{FiO}_{2}$. As a result, oxygen delivery to the alveoli is the resultant fractions of high $\mathrm{FiO}_{2}$ at a fixed delivered rate and ambient air $(0.21)$ at a rate determined by any excessive inspiratory flow generated by a patient in respiratory distress. The greater the entrainment of ambient air, the greater dilution of the alveolar $\mathrm{FiO}_{2}$. Furthermore, an additional shortcoming of COT is its lack of ability to provide any alveolar recruitment in the setting of a consolidated lung. Alveolar recruitment may result in a decreased need for excessive $\mathrm{FiO}_{2}$ delivery through recruitment of additional alveoli to participate in gas exchange. In the absence of this recruitment, a patient on COT may be exposed to unnecessarily high concentrations of inspired oxygen to maintain a sufficient saturation. The resultant negative effect of a prolonged exposure to high oxygen delivery is potentially oxygen toxicity which has been found to be associated with an increased mortality [25]. While we conceptualize oxygen toxicity as having the greatest harm in those with excessive dissolved oxygen content leading to excessive reactive oxygen species, the local toxic effect of the administration of high oxygen concentration of inspired $\mathrm{O}_{2}$ has also been described leading to tracheal and bronchial irritation, impaired mucociliary clearance and surfactant impairment, alterations in microbial flora in the upper airways and alveolar nitrogen washout leading to absorptive atelectasis. Therefore, in critically ill patients, NIV and HFNC may be more attractive options to temporize or reverse acute respiratory failure given some mechanisms described below. 


\section{Noninvasive Ventilation}

NIV refers to the delivery of positive pressure by devices other than an endotracheal tube [26]. In the critical care setting, NIV is most often delivered by application of a full oro-nasal facemask, but can be delivered through a nasal apparatus, or through use of a helmet [27]. When delivering NIV, clinicians will set an appropriate $\mathrm{FiO}_{2}$, an inspiratory positive airway pressure (IPAP) and an expiratory positive airway pressure (EPAP).

The EPAP is synonymous with positive end-expiratory pressure, commonly referred to as PEEP. This is the positive pressure level (in $\mathrm{cmH}_{2} \mathrm{O}$ ) that is present at the end of expiration [26]. IPAP refers to the level of inspiratory pressure delivered. The difference between the delivered IPAP and EPAP will determine the amount of pressure support and amount of delivered tidal volume. Nomenclature for NIV settings is best demonstrated with an example: with an IPAP of $10 \mathrm{cmH}_{2} \mathrm{O}$ and an EPAP of $5 \mathrm{cmH}_{2} \mathrm{O}$, a patient will receive a total inspiratory pressure of $10 \mathrm{cmH}_{2} \mathrm{O}$ with a PEEP of $5 \mathrm{cmH}_{2} \mathrm{O}$. This patient will receive $5 \mathrm{cmH}_{2} \mathrm{O}$ of pressure support above their baseline pressure of $5 \mathrm{cmH}_{2} \mathrm{O}$.

From a physiological perspective, the delivery of positive pressure has important implications. Positive pressure may improve arterial oxygenation through re-expansion of collapsed or atelectatic alveoli, redistribution of lung edema, and reducing areas of ventilation-perfusion mismatch [28]. Importantly, this oxygenation improvement is reliant on recruitable lung segments and avoidance of overdistension of normal pulmonary parenchyma [29]. In addition to changes in oxygenation, lung recruitment has important effects of respiratory mechanics. Lung compliance can improve when atelectatic alveoli are recruited or be reduced in situations of overdistension. These mechanisms may also result in the ability to decrease the $\mathrm{FiO}_{2}$ delivered to the patient minimizing the potential risks associated with direct toxicity related to high inspired oxygen.

Heart-lung interactions must be considered when delivering positive pressure via NIV, and the clinician should appreciate and anticipate the potential hemodynamic alterations. Classically, positive pressure can affect hemodynamic performance through a variety of mechanisms. Positive pressure delivered may result in a decrease in right ventricular preload, a variable impact on right ventricular afterload, augment left ventricular preload through propelling blood volume from the pulmonary capillaries into the left atrium, and decrease left-ventricular afterload. It can both decrease right-ventricular afterload (through improving oxygenation and reversing hypoxic vasoconstriction/decreasing pulmonary vascular resistance) or increase right-ventricular afterload in the setting of alveolar overdistension if excessive PEEP were applied. This may result in a compression in pulmonary capillaries and increasing pulmonary vascular resistance [30].

One may anticipate the potential hemodynamic response to NIV by considering the patients underlying preload status and cardiac function. With normal cardiac function, the main hemodynamic response to an increase in intrathoracic pressure is a reduction in venous return and preload to the heart, which can manifest as a reduction in cardiac output and blood pressure [28]. This phenomenon underscores the need for adequate volume repletion in patients not in cardiogenic pulmonary edema. In contrast, those patients with reduced ventricular function and signs of cardiogenic induced hydrostatic pulmonary edema can greatly benefit from NIV. The physiologic impact of reducing right-ventricular preload and afterload reducing the left ventricle is ideal in the setting of congestive heart failure and an impaired left ventricle. This can result in the redistribution of extravascular lung water [30].

Finally, NIV has an important role in hypercapnic exacerbations of chronic obstructive pulmonary disease (COPD) by decreasing the work of breathing, off-loading the respiratory muscles, counteracting intrinsic PEEP, and preventing dynamic hyperinflation [31].

Despite the potential benefits of NIV, it is important to understand its limitations and relative contraindications. For safe delivery of NIV, patients must be awake and able to protect their airway. Therefore, caution must be employed when patients have a fluctuating level of 
consciousness, poor ability to clear secretions, nausea and vomiting, or have a full stomach at risk of pulmonary aspiration [26]. Contraindications may include, but are not limited to, cardiopulmonary arrest, head and neck surgery, upper airway obstruction, fresh esophageal anastomosis, bowel obstruction, hemoptysis, and untreated pneumothorax. Another important concern with NIV is that there is a challenge in measuring the delivered tidal volumes, which, when greater than 6-8 $\mathrm{mL} / \mathrm{kg}$ of ideal body weight, may precipitate ventilator-associated lung injury $[32,33]$. NIV is a modality that has the greatest evidence in rapidly reversible conditions (congestive heart failure, acute exacerbations of chronic obstructive pulmonary disease); however, in more protracted conditions (i.e., pneumonia, checkpoint-associated pulmonary toxicities), NIV may impair one's ability to proceed with other routine care-objectives, i.e., nutrition, mobility, bronchoscopy, calling into questions its role in longer term management of more complex patients. However, increasingly, evidence have demonstrated the safety of enteral nutrition, mobilization, and bronchoscopy mechanisms with various NIV interfaces [27, 34].

\section{High-Flow Nasal Cannula}

HFNC is a novel noninvasive oxygenation device that has rapidly gained popularity. HFNC is a heated, humidified oxygen delivery system that is capable of delivering flows of $40-60 \mathrm{~L} / \mathrm{min}$ with an $\mathrm{FiO}_{2}$ of up to a $100 \%$ through specialized nasal prongs [35]. One of the major benefits of this system is that the high flow rates can match those of severely dyspneic patients, thereby preventing entrainment of room air (with an $\mathrm{FiO}_{2}$ of $21 \%$ ). This mechanism prevents dilution of delivered oxygen [10]. Furthermore, the gas is heated and humidified to avoid mucosal injury and enhance patient comfort, overcoming the key problems of past use of high flow rates [36].

In addition to supplemental oxygen, high flow rates, and humidity, several other mechanisms are hypothesized to play an important role in the clinical benefits associated with HFNC. The use of HFNC is associated with a washout of carbon dioxide from the upper airways [36, 37]. This in turn reduces anatomic dead space fraction, rebreathing of expired, carbon dioxide rich gas, and ultimately making ventilation more efficient.

High inspiratory flow rates delivered by HFNC generate low amounts of PEEP [38]. Both human and benchwork studies have determined that at $60 \mathrm{~L} / \mathrm{min}$ of flow, at least $2-4 \mathrm{cmH}_{2} \mathrm{O}$ (and perhaps even more) positive pressure can be generated. Through its flow-mediated generation of positive pressure, HFNC can improve oxygenation through recruitment of atelectatic lung regions in a mechanism comparable to NIV [36]. Given that the amount of PEEP is moderate, it may follow that the hemodynamic effects (both positive and negative) may be tempered compared to NIV.

Consistently, HFNC has been demonstrated to reduce respiratory rate, inspiratory effort, and improve oxygenation in patients with acute hypoxemic respiratory failure $[35,36,39]$ and may play an important role in the mitigation of ventilation-associated lung and diaphragmatic injury [36]. The improved breathing pattern can limit expiratory diaphragm loading $[36,40]$ and therefore possibly constrain injurious eccentric diaphragm contractions. The above described mechanisms of HFNC ultimately reduce the metabolic cost of breathing and therefore reducing minute ventilation requirements, improve lung compliance, and ventilation-perfusion matching. Importantly, these processes may reduce lung stress and strain and repetitive opening and closing of alveoli (atelectrauma) [36, 41]. Cumulatively, the improved comfort and tolerance, improved oxygenation, and theoretical reduction in diaphragm and ventilation-induced lung injury lead to the improved clinical outcomes observed with HFNC [36].

HFNC has many promising advantages as a highly effective noninvasive oxygenation device. Firstly, it permits patients to be instrumented with nasal prongs and avoids the tight-fitting masks of conventional NIV. This allows patients to eat, sleep, and clear secretions more easily than with NIV. Especially in those patients who have not previously used full face mask NIV, the use of nasal prongs and HFNC may reduce 
claustrophobia and improve uptake, compliance, and allows for continuous use of the device. Perhaps as an extension of this, patients with acute hypoxemia have consistently rated HFNC to be more comfortable than NIV [35].

Although there are many benefits of HFNC, pathophysiological states such as cardiogenic pulmonary edema where increased amounts of PEEP are needed for redistribution of alveolar lung water, NIV may be a better option. Furthermore, more studies are needed to identify those patients who are at risk of HFNC failure requiring intubation and invasive mechanical ventilation. This is of paramount importance because these patients will have little to no oxygenation reserve and are at elevated risk of significant hypoxemia during airway instrumentation.

\section{Evidence of NIV}

\section{General Population}

The role of NIV for hydrostatic pulmonary edema or to support a patient with an exacerbation of chronic obstructive pulmonary disease is compelling which recent guidelines have made strong recommendations supporting its use [42]. Its role in ARF remains controversial [31, 42, 43]. However, as a result of its effectiveness for these isolated indications, we have seen a proliferation of use across the general and oncologic population for indications beyond hydrostatic pulmonary edema and chronic obstructive pulmonary disease [44, 45].

In one of the largest, multicenter, international, observational studies evaluating the diagnosis and management patients with ARDS, the Lung Safe Study, NIV was used as a first-line therapy in 15\% of patients [46]. There was no major difference across severity of ARDS with reports of its use $(\operatorname{mild}=14 \%, \bmod =17 \%$, severe $=13 \%)$. NIV failure occurred in a moderate proportion of these patients with failure rates of $22 \%, 42 \%$, and $47 \%$ across mild, moderate, and severe ARDS, respectively. NIV failure was associated with a high mortality (45\%) across all cohorts compared to NIV success (15\% mortality). In a propensity matched analysis, NIV failure was associated with an increased ICU mortality and was found to have a greater mortality rate than those who were managed with invasive mechanical ventilation as first line with moderate-severe ARDS (i.e., $\mathrm{PaO}_{2} / \mathrm{FiO}_{2}<150$ ).

\section{Immunocompromised and Oncologic Patients}

In the immunocompromised and oncologic population, the reported rates of NIV use for ARF has been increasing since $2000[12,46]$. This increase in use overtime is likely attributable, in part to two seminal studies that hypothesized prevention of intubation would be associated with a decreased mortality.

\section{Noninvasive Ventilation in Early ARF Versus Conventional Oxygen Therapy to Prevent Intubation}

In a randomized controlled trial evaluating NIV versus COT for immunocompromised patients with early ARF, there was a significant reduction in invasive mechanical ventilation and mortality compared to patients who received COT [6]. Criteria for entry included patients who had evidence of early respiratory failure including pulmonary infiltrates, fever, dyspnea, and a $\mathrm{PaO}_{2} / \mathrm{FiO}_{2}$ less than 200 on a venturi mask. The majority of these patients were immunocompromised secondary to hematologic malignancies. NIV was applied for a median of $9 \mathrm{~h}$ per day in the first $24 \mathrm{~h}$. Of note, the control arm had a very high mortality with an increased incidence of ventilator-associated pneumonia. These results were intriguing to many and led to an increased application of NIV for oncologic patients with ARF [3, 45]. Antonelli and colleagues conducted a randomized controlled trial evaluating a similar question in 40 solid organ transplantation and found a similar reduction in invasive mechanical ventilation and mortality [8]. However, this study was noted to have a high proportion of patients with hydrostatic pulmonary edema as the primary etiology of ARF - for which there is a strong, established evidence base. Squadrone and colleagues randomized 40 patients with hematologic malignancies with bilateral infiltrations, tachypnea, and mild hypoxia (saturation $<90 \%$ on room air) to CPAP or COT as a means to 
prevent the development of acute lung injury and need for ICU admission [47]. Their study found a decreased need for admission to the ICU and need for invasive mechanical ventilation.

Given advancements oncology and hematologic malignancies, ventilator-associated pneumonia prevention, critical care management, and the small sample sizes of these seminal trials, the generalizability of these trials to current day management of oncologic patients with ARF was called into question, prompting a more recent study evaluating the role of NIV versus COT for early ARF. In the largest RCT to date of NIV versus COT for early ARF, Lemiale and colleagues randomized 374 critically ill immunocompromised patients ( $85 \%$ oncologic patients) to NIV versus COT [9]. ARF was defined the presence of $\mathrm{PaO}_{2}<60 \mathrm{mmHg}$ on room air, tachypnea, or respiratory distress. After 28 days, noninvasive oxygen strategy had failed in $38 \%$ of the NIV and $45 \%$ of the COT $(p=0.20)$, and there was no difference in the 28 -day mortality ( $24 \%$ in the NIV group vs. $27 \%$ in COT group $p=0.47$ ). Study strengths include the large sample size included and the large proportion of oncologic patients allowing its generalizability to our population of interest with ARF. Limitations included the unblinded nature of the trial, low severity of illness across the population, inclusion criteria (although it does address this question in early $\mathrm{ARF}$ ), and the use of HFNC in the COT group.

The data surrounding NIV compared to COT in the immunocompromised population was recently summarized [56]. Huang and colleagues found 5 RCTs including almost 600 patients. This group found that early NIV significantly reduced shortterm mortality (RR $0.62,95 \%$ CI $0.40-0.97, \mathrm{p}=$ 0.04 ) and intubation rate (RR $0.52,95 \%$ CI $0.32-$ $0.85, \mathrm{p}=0.01$ ) when compared with COT; however, these results were associated with significant statistical heterogeneity. The controversy and inconsistencies in patient response might be addressed in the evidence summary that follows.

\section{Noninvasive Ventilation in ARDS Versus Invasive Mechanical Ventilation (via Intubation)}

Following the publications of trials by Hilbert and Antonelli and colleagues, adoption of noninvasive ventilation beyond early acute respiratory failure was seen in the years that followed $[16,48$, 65]. Given historic reports of increased mortality with invasive mechanical ventilation, centers theorized that perhaps a noninvasive approach to management may help mitigate the deleterious consequences associated with invasive mechanical ventilation in this population (ventilator-associated pneumonia/sedation/delirium). What followed were a series of studies that evaluated the impact of NIV versus invasive mechanical ventilation on mortality in oncologic patients with ARDS [56-58].

Reported rates of NIV use for ARDS in oncologic patients are much higher ranging from $32 \%$ to $49 \%[7,16,48]$. In a post-hoc analysis of the Lung Safe study focusing on the immunocompromised population with ARDS, NIV was used in $21 \%$ of patients as the first ventilation modality of choice [65]. The application of NIV has been seen across all severities of ARDS in the setting of oncologic patients $[2,65]$. While NIV is associated with a high incidence of failure noted in the Lung Safe study (48\%) [65] across patients with ARDS, rates of failure in the oncologic population are even higher than the general ICU population ranging from $38 \%$ to $70 \%[2,16]$. NIV failure is associated with a higher in-hospital and ICU mortality (60-70\%) compared to those who experience NIV success $(28 \%)$ or invasive mechanical ventilation $(50-60 \%)$ as first-line therapy $[2,16,48]$ (Fig. 2). Pulmonary infection, increased severity of illness scores, hematologic malignancies, longer hospitalization prior to ICU admission, and severity of ARDS are consistent factors associated with NIV failure [16, 48] (Table 2). The remaining challenge is the identification of the subset who may benefit from NIV versus those in whom firstline intubation should be pursued. Table 3 outlines the evidence of NIV across oncologic patients across various severities of ARF/ARDS.

\section{Theories of Harm Associated with NIV}

\section{Injurious ventilation}

It is theorized that NIV could be associated with harm secondary to the pressure levels generated in NIV compared to pressure transmitted via low- or high-flow oxygen. During NIV, patients may generate tidal volumes that are above those considered lung protective ( $>8 \mathrm{~mL} / \mathrm{kg}$ tidal volume based upon ideal body 


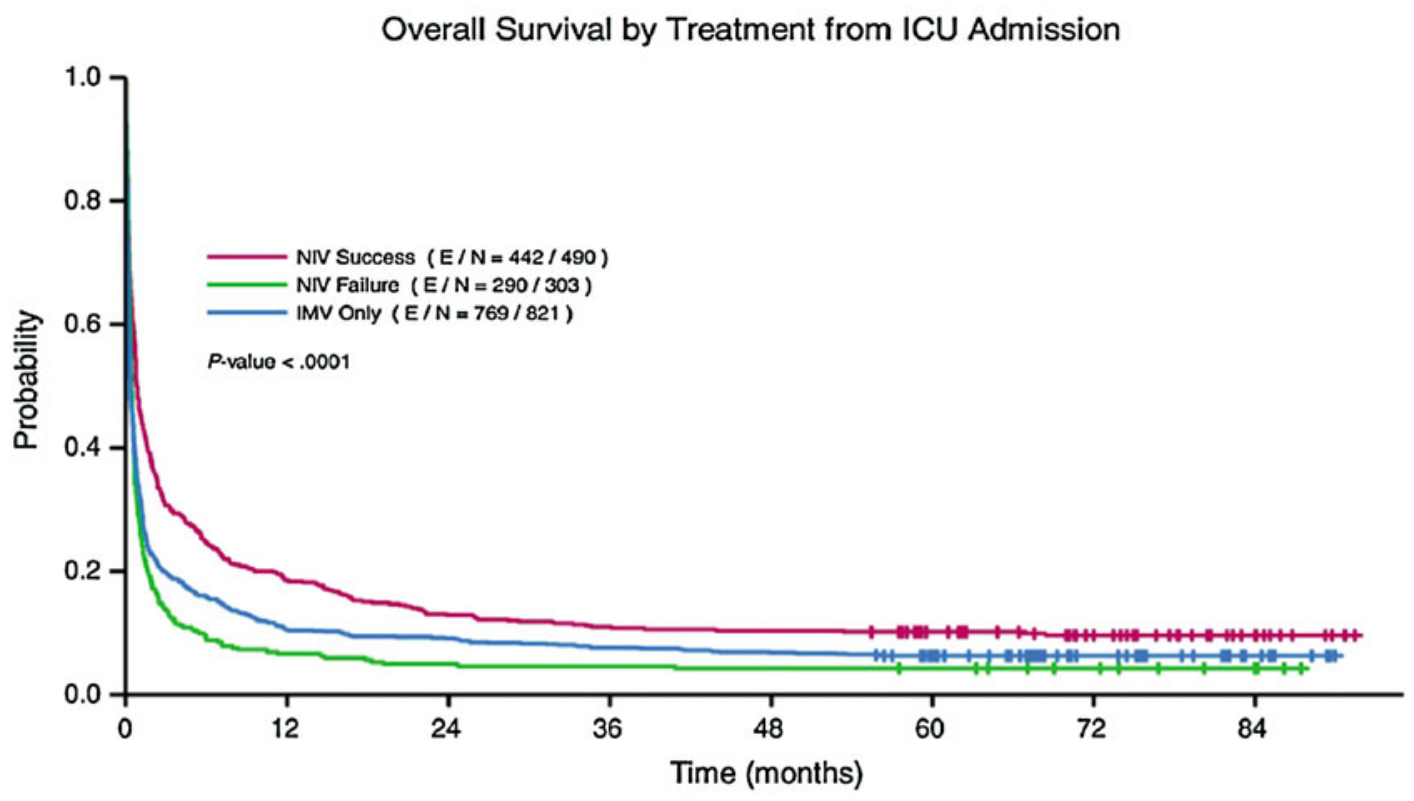

Fig. 2 Noninvasive ventilation mortality across successes and failures. Figure depicts overall survival difference in mortality across NIV success, NIV failure, and IMV. NIV noninvasive ventilation, IMV invasive ventilation

Table 2 Risk factors associated with an increased morality in oncologic patients with acute respiratory failure and noninvasive oxygen failure

\begin{tabular}{|c|c|}
\hline $\begin{array}{l}\text { Risk factors associated with an increased } \\
\text { mortality in oncologic patients with ARF }\end{array}$ & Risk factors for noninvasive oxygen therapy failure \\
\hline \multicolumn{2}{|l|}{ Demographic and clinical characteristics } \\
\hline $\begin{array}{l}\text { Hematologic malignancy, allogeneic } \\
\text { hematopoietic stem cell transplantation }\end{array}$ & Hematologic malignancy \\
\hline $\begin{array}{l}\text { Cause of respiratory failure (infectious, PJP, } \\
\text { invasive fungal infection, unclear etiology) }\end{array}$ & Pulmonary infection \\
\hline $\begin{array}{l}\text { Prolonged duration of hospitalization prior to } \\
\text { admission to ICU }\end{array}$ & Prolonged duration of hospitalization prior to admission to ICU \\
\hline \multicolumn{2}{|l|}{ Critical illness-associated features } \\
\hline Greater severity of illness & Greater severity of illness \\
\hline Worsened severity of ARDS & Worsened severity of ARDS \\
\hline NIV failure as first line oxygen therapy & $\begin{array}{l}\text { Lack of physiologic response to noninvasive ventilatory therapies } \\
\text { (i.e., drop in respiratory rate, heart rate, improvement in } \\
\text { oxygenation) evaluated early after initiation }(1-4 \mathrm{~h})\end{array}$ \\
\hline Vasopressors/renal failure & Vasopressors/renal failure \\
\hline $\begin{array}{l}\text { Tidal volume greater than } 9 \mathrm{~mL} / \mathrm{kg} 1 \mathrm{~h} \text { after } \\
\text { initiation of NIV }\end{array}$ & Tidal volume greater than $9 \mathrm{~mL} / \mathrm{kg} 1 \mathrm{~h}$ after initiation of NIV \\
\hline
\end{tabular}

$A R D S$ acute respiratory distress syndrome, $I C U$ intensive care unit, $N I V$ noninvasive ventilation, $P J P$ pneumocystis jirovecii pneumonia

weight) [68]. Injurious tidal volumes could be exacerbated in the setting of spontaneous breathing facilitating further ventilator-induced lung injury $[33,50,51]$. This, in turn, could worsen hypoxemia and generate conditions requiring invasive mechanical ventilation and multisystem organ failure. Immunocompromised patients typically present to ICU with higher illness 


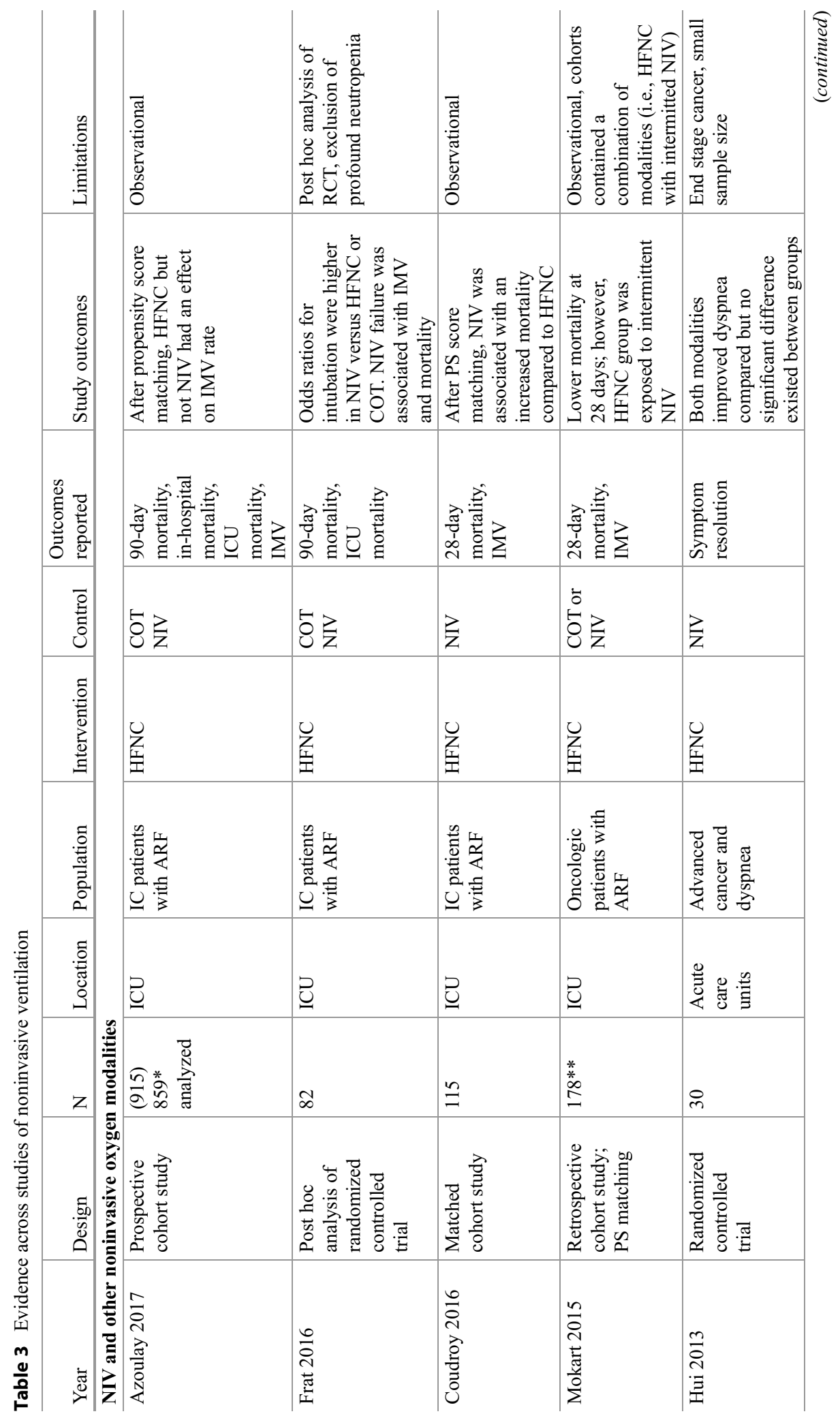




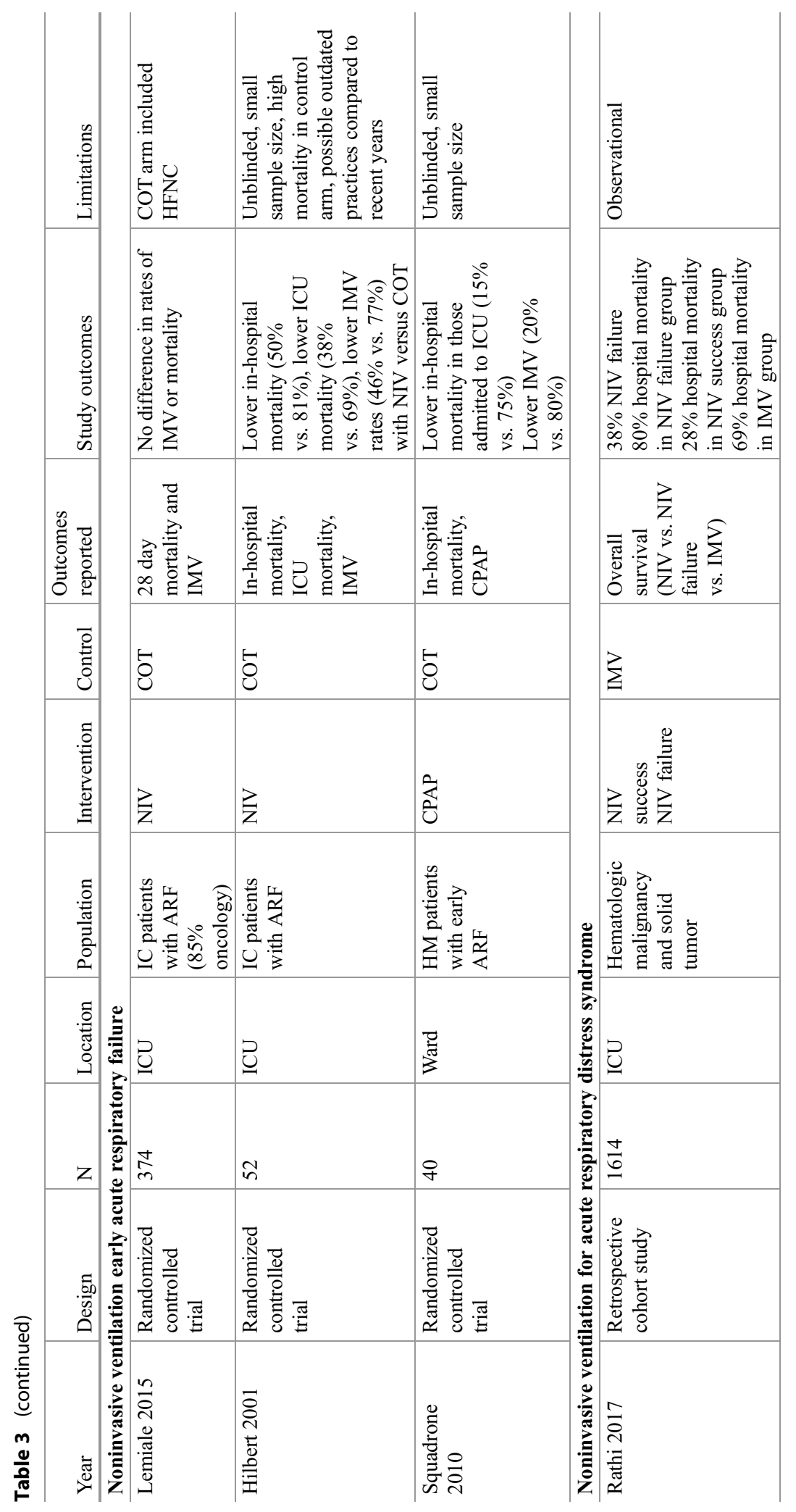




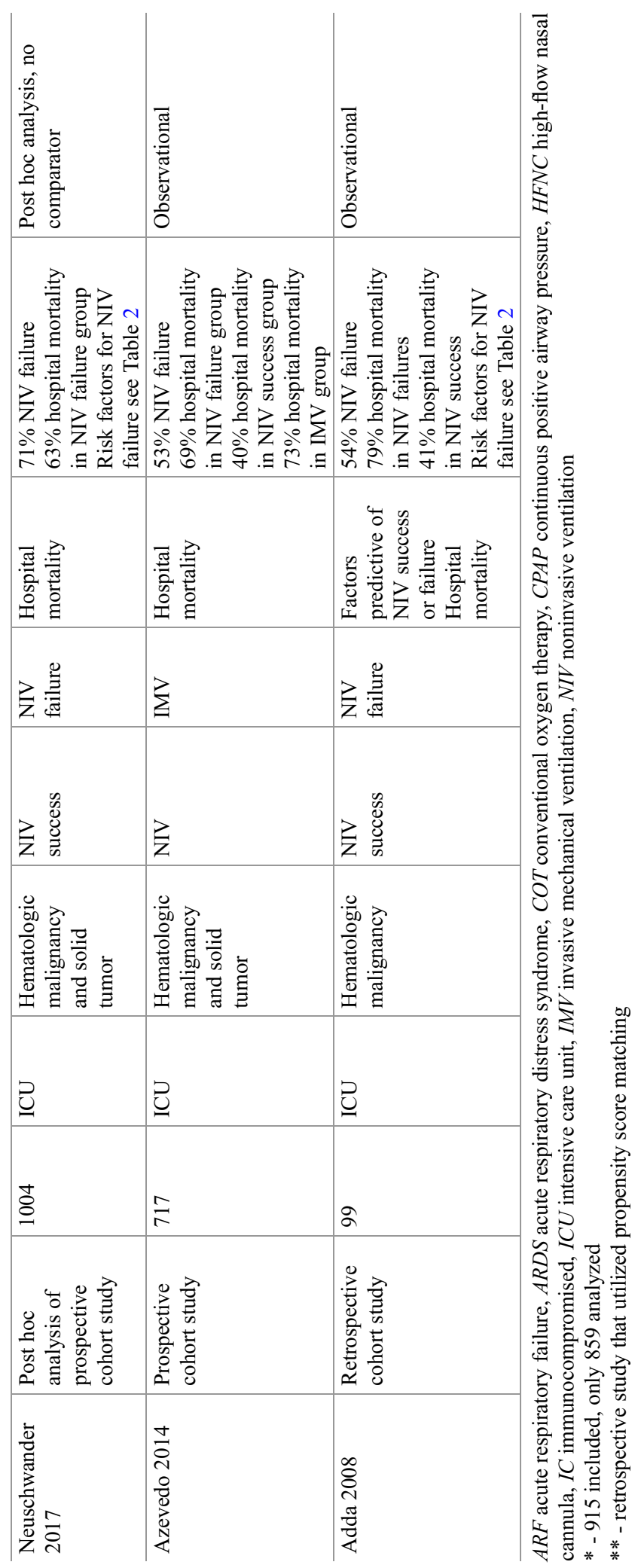


severity and multiple organ dysfunction [2] and are therefore at higher risk of ventilationassociated lung injury, potentially exacerbated by injurious tidal volumes during NIV.

2. Delay in intubation

It is further theorized that prolonged NIV without evidence of respiratory improvement may lead to a delay in intubation. In previous studies of patients with ARDS, there is a suggestion that a longer duration of NIV in those requiring intubation, the greater the mortality compared to those intubated sooner [51]; however, this was not found across a retrospective studies focused specifically on oncologic patients [16]. A delay in intubation or prolonged NIV prior to intubation potentially creates a setting of lower respiratory reserve, risk of aspiration pneumonitis, or potential greater instability around induction for intubation.

3. ICU evidence-based care

NIV may prevent ongoing evidence-based ICU care including mobilization, transport for imaging, enteral nutrition, and invasive diagnostic tests such as bronchoalveolar lavage. Sufficient recruitment to achieve adequate oxygenation may not be possible due to the facemask interface or discomfort by the patient.

\section{Is There a Role for NIV in Oncologic Patients with ARDS?}

The subset of those who experience NIV success consistently have been found to have the lowest mortality rate compared to those who undergo first-line invasive mechanical ventilation or fail NIV [16, 48]. Rates of NIV success have varied from reports across different institutions which may reflect important differences in patient selection and practice. Accurate identification of those who are at highest risk of NIV failure versus success is paramount to potentially defining any role for NIV in the setting of ARDS for oncologic patients. Datato-date is limited by its retrospective nature subjecting it to selection bias - those who experience NIV failure are patients that the intensivist may not be keen to intubate given poor overall prognostic factors and therefore turned to NIV first line. Until further research clarifies its role in ARDS in oncologic patients, it should be reserved for those patients in which one suspects underlying hydrostatic pulmonary edema as a plausible cause of ARF or contributor, or be applied for a time limited trial ( 1 or $4 \mathrm{~h}$ ) in those with a low severity of illness with an early evaluation of physiologic improvement (decrease in respiratory rate, drop in $\mathrm{FiO}_{2}$ requirements - Fig. 3). In the study by Rathi and colleagues, they evaluated improvement in respiratory rate, Glasgow coma score, oxygenation parameters, and acid-base status as markers of NIV success (and thus continuation) or NIV failure (potential indication to consider intubation) [16]. Frat and colleagues also evaluated factors associated with NIV failure. At $1 \mathrm{~h}$ following initiation, a persistent $\mathrm{PaO}_{2} /$ $\mathrm{FiO}_{2}<200$ and tidal volumes greater than $9 \mathrm{~mL} /$ $\mathrm{kg}$ of predicted body weight were independently associated with the need for invasive mechanical ventilation and mortality [52]. It would be important that the intensivist considers (1) tidal volumes generated, (2) need for other invasive tests or imaging (CT/fiberoptic bronchoscopy), and (3) immediate response to its application with a projected rapid wean-off of NIV (i.e., drop in respiratory rate/oxygenation response). Furthermore, Patel and colleagues recently evaluated the interface of helmet versus face mask for NIV and found a decreased need for invasive mechanical ventilation and morality [27]. These findings are intriguing for which its role needs to be further elucidated in this population compared to alternative noninvasive oxygen strategies outlined below.

\section{Evidence for HFNC}

\section{General Population}

HFNC has recently emerged as a safe and comfortable device with a means to effectively administer high-flow oxygen to patients with ARF. Emerging data has demonstrated promising results compared to alternative noninvasive oxygen strategies (Table 4). In one of the largest RCTs to date, Frat and colleagues randomized 310 patients with ARF to HFNC versus COT versus NIV [32]. HFNC was associated with a lower incidence of 90-day mortality compared to the COT and NIV. In the subgroup of patients with a $\mathrm{PaO}_{2} / \mathrm{FiO}_{2}<200$, 


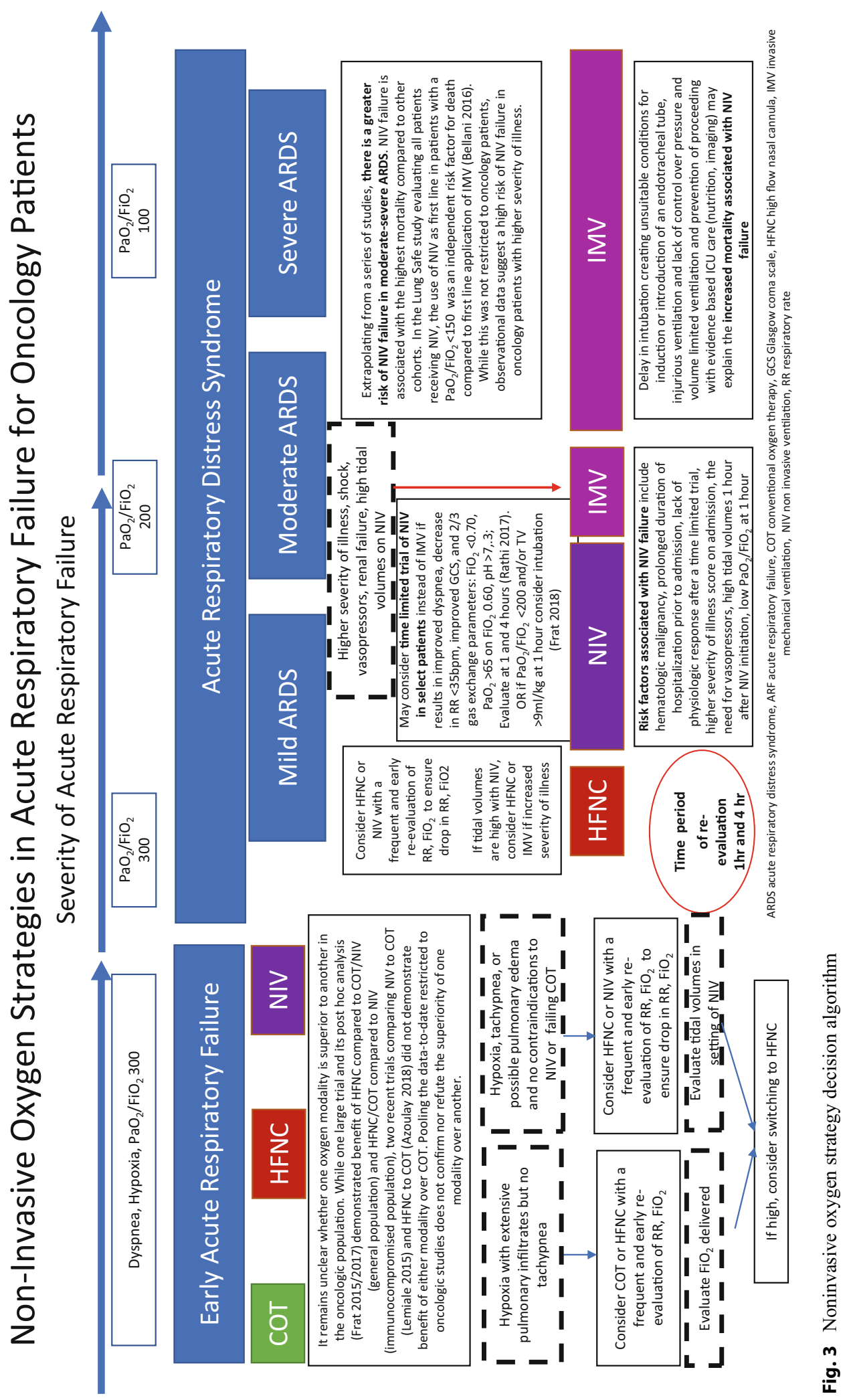




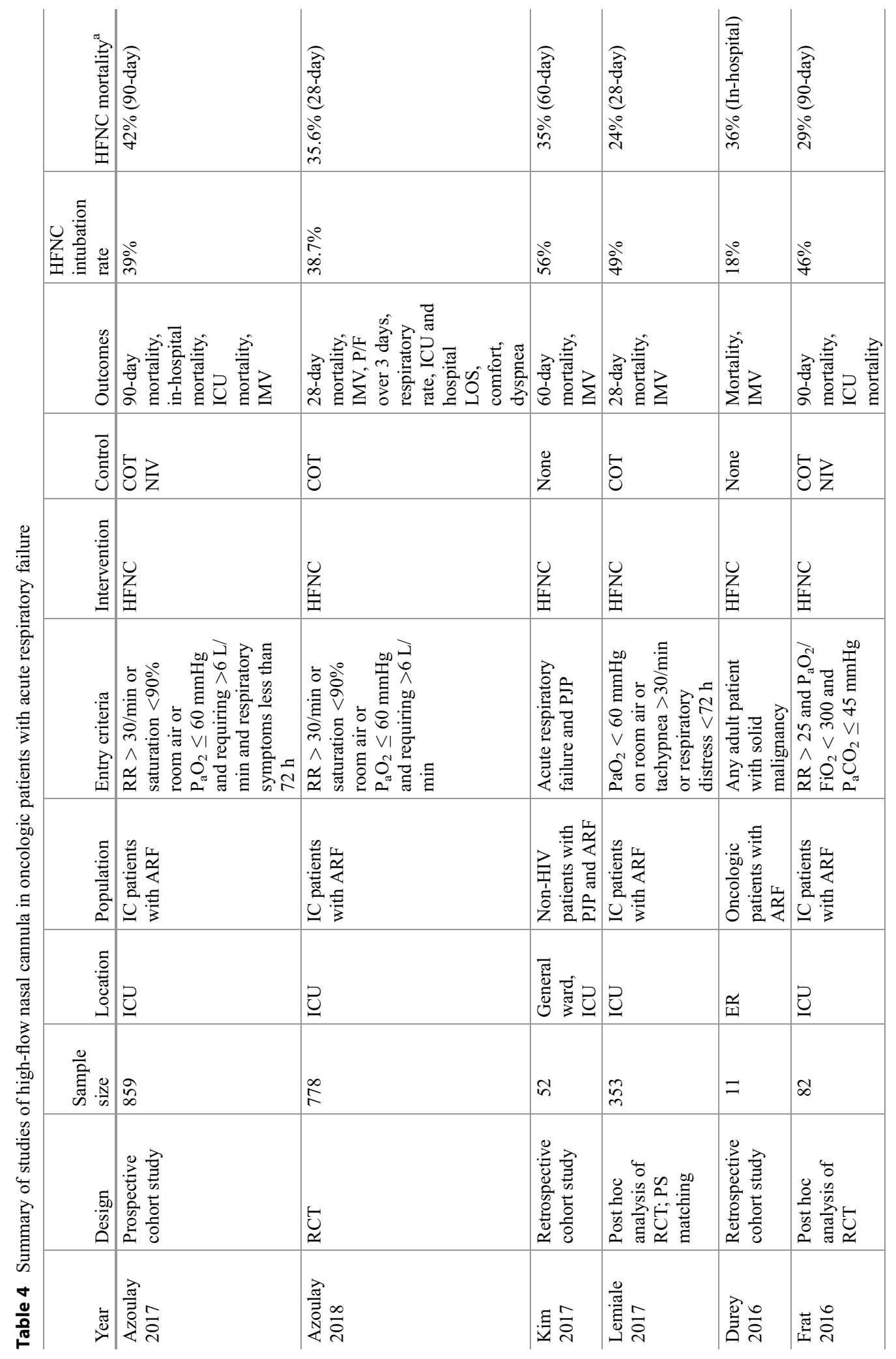




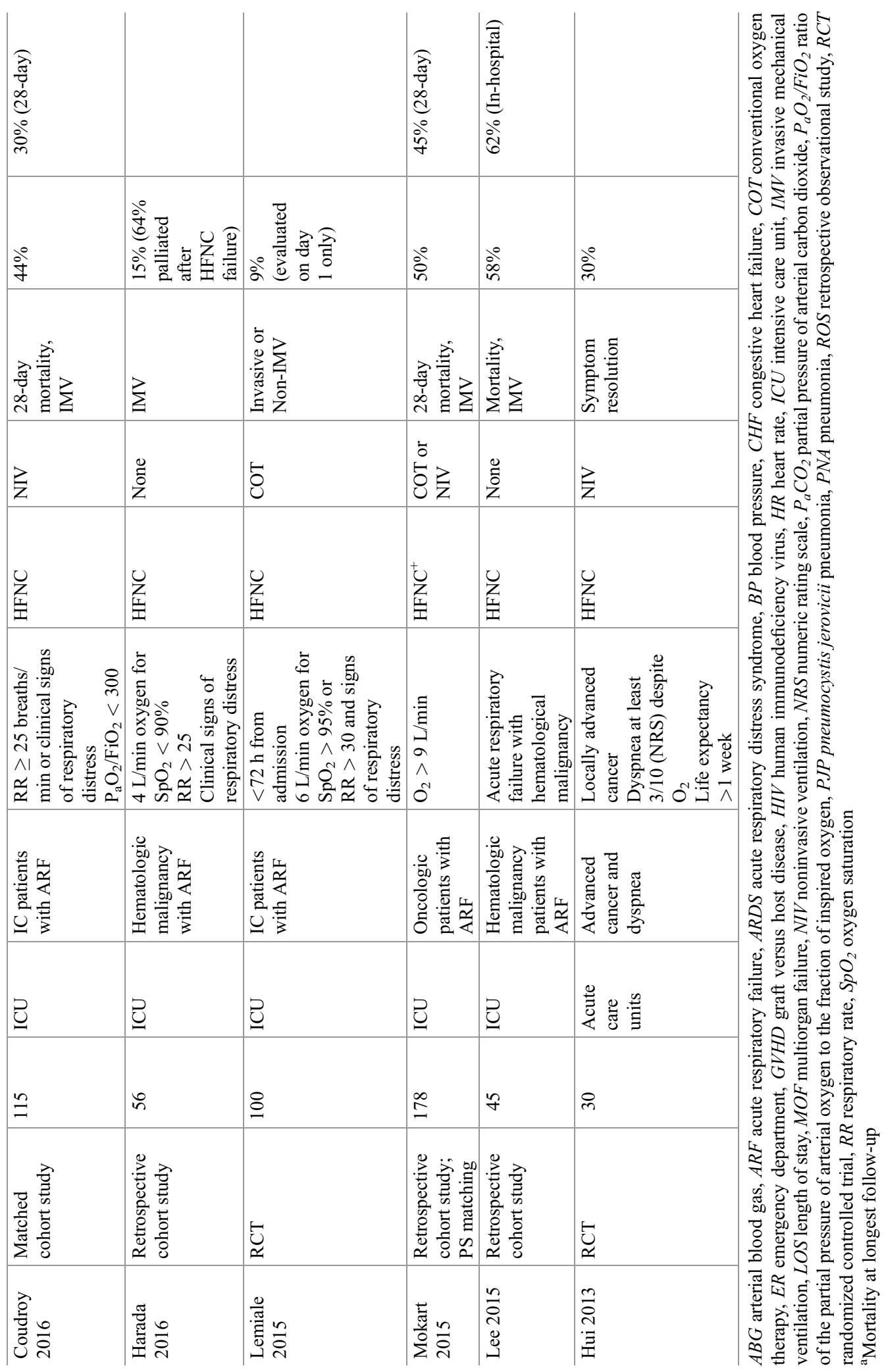


HFNC was associated with a lower incidence of invasive mechanical ventilation. However, the signal of benefit has not been consistent across all studies. A Cochrane review by Corley and colleagues evaluated the use of HFNC compared to COT or NIV for ARF or postextubation across 11 RCTs [53]. HFNC compared to COT was not associated with lower rates of invasive mechanical ventilation (reported in six studies) or mortality (reported in three studies). Confidence in the results using GRADE criteria [54] was downgraded to low given the risk of bias across these studies and different participant indications. Data comparing HFNC to NIV was not pooled given the low number of studies and their heterogeneity.

\section{Immunocompromised and Oncologic Population}

Given the important differences in the oncologic population and the general ICU population and evolving evidence of potential harm associated with NIV failure, HFNC has emerged as a promising modality in this population. High quality data evaluating use of HFNC compared to COT or NIV in this population is unfortunately limited. In a multinational, prospective observational study across 16 countries of immunocompromised patients with ARF (87\% oncologic), noninvasive oxygen strategies were evaluated in 915 patients [12]. Fifty-three percent received COT, $17 \%$ received NIV, 20\% received HFNC, and $9 \%$ received a combination of HFNC and NIV. After propensity score matching, HFNC had an impact on invasive mechanical ventilation but not NIV. HFNC was not independently associated with a lower mortality.

In a post hoc analysis of the RCT by Frat and colleagues evaluating HFNC versus COT and NIV, outcomes across the cohort of 82 immunocompromised patients ( $44 \%$ oncology) were evaluated [68]. NIV was associated with an increased need for invasive mechanical ventilation compared to HFNC or COT.

Finally, in a post hoc propensity score-matched analysis by Lemiale and colleagues of their prior RCT (NIV vs. COT) [9], they compared 90 patients who received HFNC in their control group matched to 90 patients who received COT in their control group [55]. They found no difference in the rates of invasive mechanical ventilation or mortality.

Sklar and colleagues recently described the role of HFNC compared to any noninvasive oxygen control (COT or NIV) across immunocompromised patients (13 studies) [66]. Data from RCTs and observational studies that used matching techniques were meta-analyzed ( 8 studies). Mortality was found to be lower at the longest available follow-up with HFNC compared to the oxygen control groups (NIV or COT - 7 studies; 1429 patients, relative risk of $0.72,95 \% \mathrm{CI}$ $0.56-0.93, p=0.01$ ). There was a lower rate of invasive mechanical ventilation with HFNC compared to the oxygen therapy controls across 8 studies ( 8 studies, 1529 patients, relative risk of 0.81 , $95 \%$ CI $0.67-0.96, p=0.02$ ). However, one of the limitations of this analysis was the pooling of the two control arm techniques and the inclusion of observational studies in the analysis.

Eleven studies have evaluated the use of HFNC specifically in oncologic patients (Table 4) reporting on 1,881 patients.

These studies included 6 retrospective, cohort studies [59, 60, 62-64], 1 prospective observational study [12], and 4 RCTs, 2 of which were post hoc analyses of previous RCTs outlined above $[9,55,61,68]$. Eight studies compared HFNC to an oxygen therapy control (NIV or COT). Oncologic diagnosis or treatment associated effect was the leading cause of immunosuppression with a predominance of hematologic malignancy $(9 / 11$ studies). HFNC was initiated in the emergency department, acute care ward, or intensive care unit with the latter being the most common site of initiation. Various indications for the application of HFNC existed ranging from tachypnea or hypoxia on room air to more formalized $\mathrm{PaO}_{2} / \mathrm{FiO}_{2}$ thresholds. The median $\mathrm{PaO}_{2} / \mathrm{FiO}_{2}$ across the studies was 145 (IQR 115-175). The need for invasive mechanical ventilation, evaluated at 28 -day intubation or hospital discharge, was $46 \%$ (IQR 25-67\%). The longest follow-up mortality time points are reported in Table 3 with a median mortality of $36 \%$ (IQR $14-58 \%$ ).

Mortality at longest available follow-up and the need for invasive mechanical ventilation was reported in 7 and 8 studies, respectively (Table 4). 
Mortality at Longest Available Follow Up for HFNC compared to NIV

\begin{tabular}{|c|c|c|c|c|c|c|c|c|c|c|c|}
\hline \multirow[b]{2}{*}{ Study or Subgroup } & \multicolumn{2}{|c|}{ HFNC } & \multicolumn{2}{|c|}{ NIV } & \multicolumn{3}{|c|}{ Risk Ratio } & \multirow{2}{*}{\multicolumn{4}{|c|}{$\begin{array}{c}\text { Risk Ratio } \\
\text { IV, Random, } 95 \% \text { Cl }\end{array}$}} \\
\hline & Events & Total & Events & Total & Weight & IV, Random, $95 \% \mathrm{Cl}$ & Year & & & & \\
\hline Coudroy 2016 & 12 & 60 & 22 & 55 & $32.3 \%$ & $0.50[0.27,0.91]$ & 2016 & & & & \\
\hline Frat 2016 & 4 & 26 & 12 & 26 & $19.2 \%$ & $0.33[0.12,0.90]$ & 2016 & & & & \\
\hline Azoulay 2017 & 78 & 187 & 74 & 153 & $48.5 \%$ & $0.86[0.68,1.09]$ & 2017 & & & & \\
\hline Total $(95 \% \mathrm{Cl})$ & & 273 & & 234 & $100.0 \%$ & $0.60[0.35,1.04]$ & & & & & \\
\hline Total events & 94 & & 108 & & & & & & & & \\
\hline \multicolumn{8}{|c|}{ Heterogeneity: $\mathrm{Tau}^{2}=0.14 ; \mathrm{Chi}^{2}=5.61, \mathrm{df}=2(\mathrm{P}=0.06) ; \mathrm{I}^{2}=64 \%$} & 0.01 & 0.1 & 10 & 100 \\
\hline \multicolumn{8}{|c|}{ Test for overall effect: $Z=1.83(P=0.07)$} & & Favours [HFNC] & Favours [NIV] & \\
\hline
\end{tabular}

Mortality at Longest Available Follow Up for HFNC compared to COT

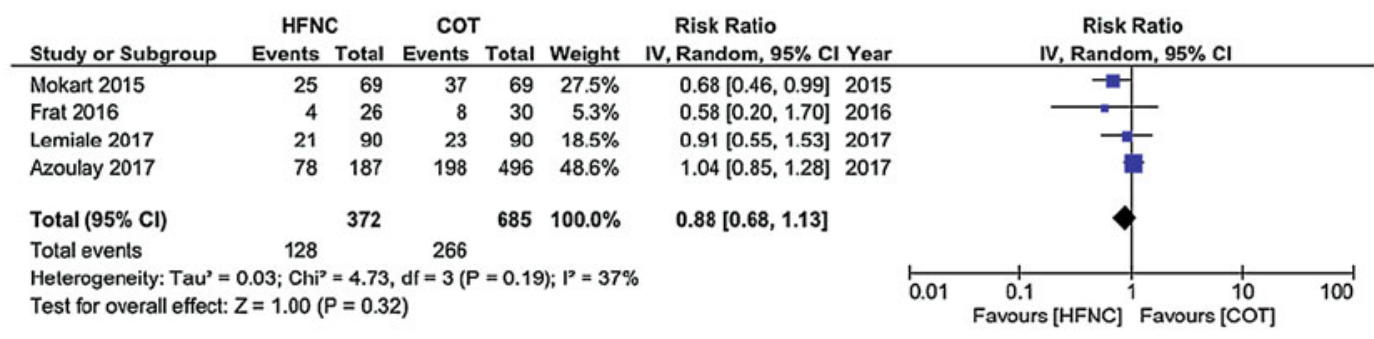

Need for Invasive Mechanical Ventilation for HFNC compared to NIV

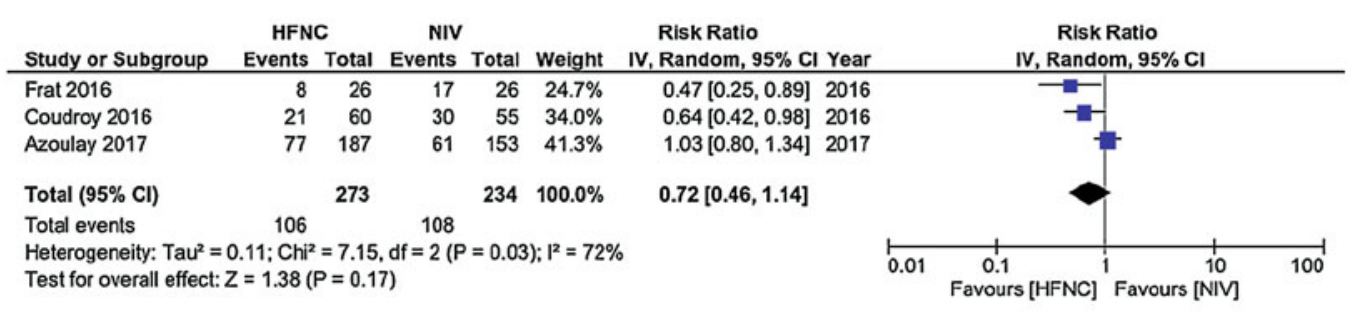

Need for Invasive Mechanical Ventilation for HFNC compared to COT

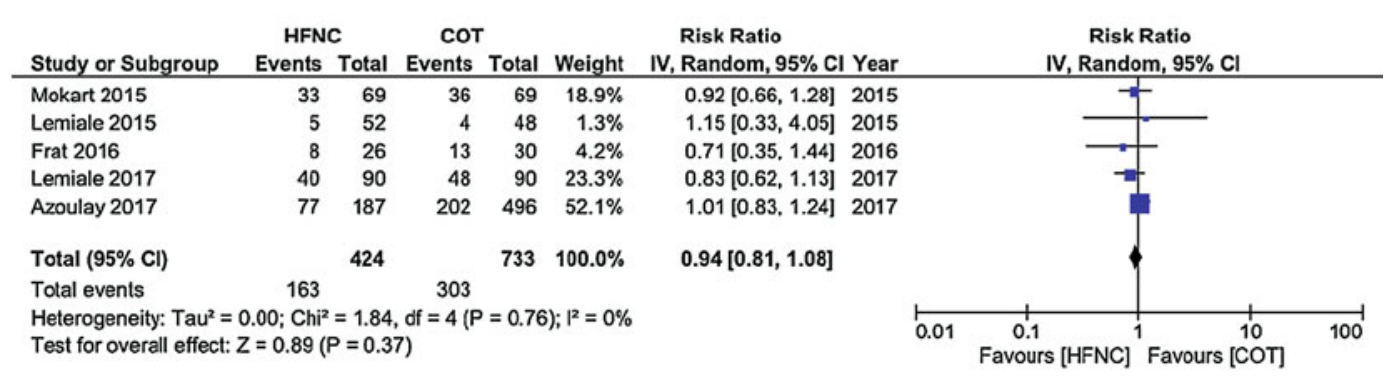

Fig. 4 Mortality and invasive mechanical ventilation across high-flow nasal cannula studies. This figure compares the effect of HFNC compared to NIV and COT on mortality at the longest available follow-up and need for invasive mechanical ventilation. Data are pooled using an

Using a random effects model, HFNC compared to NIV or COT was not associated with a decreased mortality or need for invasive mechanical ventilation (Fig. 4) (unpublished work). These findings inverse variance random effects model. Results are summarized as risk ratios. (Oncologic subgroup of studies extrapolated from a systematic review evaluating HFNC compared to other modalities-unpublished data)

are primarily meant to be exploratory given the heterogeneous nature of the populations and low quality of evidence (observational studies, post hoc analyses of RCTs). 
Most recently, Azoulay and colleagues performed the largest RCT to date of immunocompromised patients with ARF and randomized the approximately 800 patients to COT or HFNC [67]. These patients were mainly immunocompromised secondary to hematologic malignancy or its treatments. The primary outcome of 28-day survival was not different between the two groups $(35.6 \%$ HFNC vs. $36.1 \%$ COT), nor were a number of secondary outcomes including intubation rates, ICU and hospital length of stay, or ICU-related complications. This trial therefore suggests that HFNC in all immunocompromised patients may not be better than COT and further subgroups of HFNC "responders" must be sought. Future directions would necessitate larger, randomized controlled trials specifically enrolling oncologic patients comparing COT, NIV, and HFNC head-to-head. In addition, there could exist a differential impact across varying severities and indications for ARF.

In deciding optimal noninvasive oxygen therapy, one needs to consider the etiology, timing of reversal, severity of illness, impact of the modality on tidal volumes, and immediate response of respiratory physiology variables and tidal volumes to the modality chosen $[16,52]$. Figure 3 represents a proposed algorithm for consideration of noninvasive oxygen therapies and factors to consider in deciding upon first-line and second-line modalities. The figure attempts to capture some important factors that should be considered in deciding upon modality of choice.

\section{Conclusions}

COT, NIV, and HFNC are multimodal techniques to administer oxygen noninvasively in critically ill patients with ARF. Each has unique mechanisms, advantages, and disadvantages. Until further research is available, individual patient characteristics, severity of illness, and early response to each modality is imperative to guide selection of which strategy is most applicable. Most importantly, the physician needs to pay meticulous attention to the rapidity of reversibility of the underlying condition and reevaluate the impact of the strategy chosen at an early time points (e.g., 1 and 4 h). An improved physiologic response to the modality of choice has been consistently found to be associated with success. While HFNC is a unique oxygen delivery modality that holds theoretical promise for the treatment of ARF in oncologic patients, the current body of literature demonstrates that there is a paucity of high-quality data in this specific population to guide evidence-based therapy. This chapter underscores the need for further research with clinical and physiological studies, including larger randomized controlled trials specifically of oncologic patients to more clearly elucidate the potential benefits of one modality over another.

\section{References}

1. Nava S, Cuomo AM. Acute respiratory failure in the cancer patient: the role of noninvasive mechanical ventilation. Crit Rev Oncol Hematol. 2004;51(2):91-103.

2. Azoulay E, Lemiale V, Mokart D, et al. Acute respiratory distress syndrome in patients with malignancies. Intensive Care Med. 2014;40(8):1106-15.

3. Cortegiani A, Madotto F, Gregoretti C, et al. Immunocompromised patients with acute respiratory distress syndrome: secondary analysis of the LUNG SAFE database. Crit Care. 2018;22:157-72.

4. Adda M, Coquet I, Darmon M, et al. Predictors of noninvasive ventilation failure in patients with hematologic malignancy and acute respiratory failure. Crit Care Med. 2008;36(10):2766-72.

5. Darmon MR, Bernal T, et al. Ventilatory support in critically ill hematology patients with respiratory failure. Crit Care. 2012;16(4):R133.

6. Hilbert G, Gruson D, Vargas F, et al. Noninvasive ventilation in immunosuppressed patients with pulmonary infiltrates. N Engl J Med. 2001;344:481-7.

7. Azevedo LCP, Caruso P, Silva UVA, et al. Outcomes for patients with cancer admitted to the ICU requiring ventilatory support: results from a prospective multicenter study. Chest. 2014;146(2):257-66.

8. Antonelli M, Conti G, Bufi M, et al. Noninvasive ventilation for treatment of acute respiratory failure in patients undergoing solid organ transplant: a randomized trial. JAMA. 2000;283:235-41.

9. Lemiale V, Mokart D, Resche-Rigon M, et al. Effect of noninvasive ventilation vs oxygen therapy on mortality among immunocompromised patients with acute respiratory failure: a randomized clinical trial. JAMA. 2015;314(16):1711-9.

10. Schellongowski P, Sperr W, Wohlfarth P, et al. Critically ill patients with cancer: chances and limitations of intensive care medicine - a narrative review. ESMO Open. 2016;1:e00018. 
11. Azoulay E, Mokart D, Penne F, et al. Outcomes of critically ill patients with hematologic malignancies: prospective multicenter data From France and Belgium - a groupe de recherche respiratoire en réanimation oncohématologique study. J Clin Oncol. 2013;31(22):2810-8.

12. Azoulay E, Pickkers P, Soares M, et al. Acute hypoxemic respiratory failure in immunocompromised patients: the Efraim multinational prospective cohort study. Intensive Care Med. 2017;43:1808-19.

13. Weijs PJM, Looijaard WGPM, Dekker IM, et al. Low skeletal muscle area is a risk factor for mortality in mechanically ventilated critically ill patients. Crit Care. 2014;18(2):R12.

14. Moisey LL, Mourtzakis M, Cotton BA, et al. Skeletal muscle predicts ventilator-free days, ICU-free days, and mortality in elderly ICU patients. Crit Care. 2013;17(5):R206.

15. Cesari M, Landi F, Vellas B, et al. Sarcopenia and physical frailty: two sides of the same coin. Front Aging Neurosci. 2014;6:192.

16. Rathi N, Haque S, Nates R. Non-invasive positive pressure ventilation vs invasive mechanical ventilation as first-line therapy for acute hypoxemic respiratory failure in cancer patients. J Crit Care. 2017;39:56-61.

17. Afessa B, Peters SG. Major complications following hematopoietic stem cell transplantation. Semin Respir Crit Care Med. 2006;27(3):297-309.

18. Herridge MS, Tansey CM, Matté A, et al. Functional disability 5 years after acute respiratory distress syndrome. N Engl J Med. 2011;364(14):1293-304.

19. Taccone F, Artigas A, Sprung C, et al. Characteristics and outcomes of cancer patients in European ICUs. Crit Care. 2009;13:R15.

20. Van Vliet M, Verburg I, Boogaard M. Trends in admission prevalence, illness severity and survival of hematological patients treated in Dutch intensive care units. Intensive Care Med. 2014;40:1275-84.

21. Squadrone V, Ferreyra G, Ranieri V. Non-invasive ventilation in patients with hematologic malignancy: a new prospective. Minerva Anestesiol. 2015;81(10):1118.

22. Kotloff RM, Ahya VN, Crawford F. Pulmonary complications of solid organ and hematopoietic stem cell transplantation. Am J Respir Crit Care Med. 2004; 170:22-48.

23. Lucena CM, Torres A, Rovira M, et al. Pulmonary complications in hematopoietic SCT: a prospective study. Bone Marrow Transplant. 2014;49:1293-9.

24. Bateman NT, Leach RM. ABC of oxygen. Acute oxygen therapy. BMJ. 1998;317:798-801.

25. Chu D, Kim L, Young P, et al. Mortality and morbidity in acutely ill adults treated with liberal versus conservative oxygen therapy (IOTA): a systematic review and meta-analysis. Lancet. 2018;391:1693-705.

26. Mehta S, Hill NS. Non-invasive ventilation. Am J Respir Crit Care Med. 2001;163:540-77.

27. Patel BK, Wolfe KS, Pohlman AS, et al. Effect of noninvasive ventilation delivered by helmet vs face mask on the rate of endotracheal intubation in patients with acute respiratory distress syndrome: a randomized clinical trial. JAMA. 2016;315:2435-41.
28. Lenique F, Habis M, Lofaso F, et al. Ventilatory and hemodynamic effects of continuous positive airway pressure in left heart failure. Am J Respir Crit Care Med. 1997;155:500-5.

29. Mertens M, Tabuchi A, Meissner S, et al. Alveolar dynamics in acute lung injury: heterogeneous distension rather than cyclic opening and collapse. Crit Care Med. 2009;37:2604-11.

30. Chadda K, Annane D, Hart N, et al. Cardiac and respiratory effects of continuous positive airway pressure and noninvasive ventilation in acute cardiac pulmonary edema. Crit Care Med. 2002;30:2457-61.

31. Brochard L, Mancebo J, Wysocki M, et al. Noninvasive ventilation for acute exacerbations of chronic obstructive pulmonary disease. N Engl J Med. 1995; 333:817-22.

32. Frat J-P, Thille AW, Mercat A, et al. High-flow oxygen through nasal cannula in acute hypoxemic respiratory failure. N Engl J Med. 2015;372:2185-96.

33. Brochard L, Slutsky A, Pesenti A. Mechanical ventilation to minimize progression of lung injury in acute respiratory failure. Am J Respir Crit Care Med. 2017;195:438-42.

34. Agarwal R, Khan A, Aggarwal AN, et al. Bronchoscopic lung biopsy using noninvasive ventilatory support: case series and review of literature of NIV-assisted bronchoscopy. Respir Care. 2012;57(11):1927-36.

35. Papazian L, Corley A, Hess D, et al. Use of high-flow nasal cannula oxygenation in ICU adults: a narrative review. Intensive Care Med. 2016;42:1336-49.

36. Goligher EC, Slutsky AS. Not just oxygen? Mechanisms of benefit from high-flow nasal cannula in hypoxemic respiratory failure. Am J Respir Crit Care Med. 2017;195:1128-31.

37. Möller W, Feng S, Domanski U, et al. Nasal high flow reduces dead space. J Appl Physiol. 2017;122:191-7.

38. Parke R, McGuinness S, Eccleston M. Nasal high-flow therapy delivers low level positive airway pressure. Br J Anaesth. 2009;103:886-90.

39. Rittayamai N, Tscheikuna J, Praphruetkit N, et al. Use of high-flow nasal cannula for acute dyspnea and hypoxemia in the emergency department. Respir Care. 2015;60:1377-82.

40. Pellegrini M, Hedenstierna G, Roneus A. The diaphragm acts as a brake during expiration to prevent lung collapse. Am J Respir Crit Care Med. 2016;195:1608-16.

41. Cressoni M, Chiumello D, Algieri I, et al. Opening pressures and atelectrauma in acute respiratory distress syndrome. Intensive Care Med. 2017;43:603-11.

42. Rochwerg B, Brochard L, Elliott M, et al. Official ERS/ATS clinical practice guidelines: noninvasive ventilation for acute respiratory failure. Eur Respir J. 2017;50:1602426.

43. Vital FM, Ladeira MT, Atallah AN. Non-invasive positive pressure ventilation (CPAP or bilevel NPPV) for cardiogenic pulmonary oedema. Cochrane Database Syst Rev. 2013;5:CD005351.

44. Mehta A, Douglas I, Walkey A. Evidence-based utilization of noninvasive ventilation and patient outcomes. Ann Am Thorac Soc. 2017;14(11):1667-73. 
45. Bellani G, Laffey J, Pham T. Noninvasive ventilation of patients with acute respiratory distress syndrome: insights from the LUNG SAFE Study. Am J Respir Crit Care Med. 2017;195(1):67-77.

46. Bellani G, Laffey J, Pham T, et al. Epidemiology, patterns of care, and mortality for patients with acute respiratory distress syndrome in intensive care units in 50 countries. JAMA. 2016;315(8):788-800.

47. Squadrone V, Massaia M, Bruno B, et al. Early CPAP prevents evolution of acute lung injury in patients with hematologic malignancy. Intensive Care Med. 2010; 36(10):1666.

48. Neuschwander A, Lemiale V, Darmon M, et al. Noninvasive ventilation during acute respiratory distress syndrome in patients with cancer: trends in use and outcome. J Crit Care. 2017;38:295-9.

49. Brochard L. Ventilation-induced lung injury exists in spontaneously breathing patients with acute respiratory failure: yes. Intensive Care Med. 2017;43(2):250-2.

50. Amato MBP, Meade MO, Slutsky AS, et al. Driving pressure and survival in the acute respiratory distress syndrome. N Engl J Med. 2015;372(8):747-56.

51. Esteban A, Frutos-Vivar F, Ferguson ND, et al. Noninvasive positive-pressure ventilation for respiratory failure after extubation. N Engl J Med. 2004;350(24):245-54.

52. Frat JP, Ragot S, Coudroy R, et al. Predictors of intubation in patients with acute hypoxemic respiratory failure treated with a noninvasive oxygenation strategy. Crit Care Med. 2018;46(2):208-15.

53. Corley A, Rickard C, Aitken L, et al. High flow nasal cannulae for respiratory support in adult intensive care patients. Cochrane Database Syst Rev. 2017; 5:CD010172.

54. Higgins JPT, Green S. Cochrane handbook for systematic reviews of interventions. Hoboken: Wiley; 2011.

55. Lemiale V, Resche-Rigon M, Mokart D, et al. High-flow nasal cannula oxygenation in immunocompromised patients with acute hypoxemic respiratory failure: A Groupe de Recherche Respiratoire en Réanimation Onco-Hématologique Study. Crit Care Med. 2017;45(3):e274-81.

56. Liu J, Bell C, Campbell V, et al. Noninvasive ventilation in patients with hematologic malignancy. J Intensive Care Med. 2017. https://doi.org/10.1177/ 0885066617690725 . Epub ahead of print.

57. Huang H-B, Xu B, Liu G-Y, et al. Use of noninvasive ventilation in immunocompromised patients with acute respiratory failure: a systematic review and metaanalysis. Crit Care. 2017;21(1):4-29.

58. Wang T, Zhang L, Luo K, et al. Noninvasive versus invasive mechanical ventilation for immunocompromised patients with acute respiratory failure: a systematic review and meta-analysis. BMC Pulm Med. 2016;16:129-43.

59. Lee HY, Rhee CK, Lee JW. Feasibility of high-flow nasal cannula oxygen therapy for acute respiratory failure in patients with hematologic malignancies: a retrospective single-center study. J Crit Care. 2015; 30(4):773-8.

60. Durey A, Kang S, Suh Y, et al. Application of highflow nasal cannula to heterogeneous condition in the emergency department. Am J Emerg Med. 2017; 35(8):1199-201.

61. Hui D, Morgado M, Chisholm G, et al. High-flow oxygen and bilevel positive airway pressure for persistent dyspnea in patients with advanced cancer: a phase II randomized trial. J Pain Symptom Manage. 2013; 46(4):463-80.

62. Coudroy R, Jamet A, Petua P, et al. High-flow nasal cannula oxygen therapy versus noninvasive ventilation in immunocompromised patients with acute respiratory failure: an observational cohort study. Ann Intensive Care. 2016;6(1):45-56.

63. Mokart D, Geay C, Chow-Chine L, et al. High-flow oxygen therapy in cancer patients with acute respiratory failure. Intensive Care Med. 2015;41(11): 2008-10.

64. Kim WY, Sung H, Hong SB, et al. Predictors of high flow nasal cannula failure in immunocompromised patients with acute respiratory failure due to non-HIV pneumocystis pneumonia. J Thorac Dis. 2017;9(9): 3013-22.

65. Cortegiani A, Madotto F, Gregoretti C et al. Immunocompromised patients with acute respiratory distress syndrome: secondary analysis of the LUNG SAFE database. Critical Care. 2018;22:157-172.

66. Sklar MC, Mohammed A, Orchanian-Cheff A et al. The impact of high-flow nasal oxygen in the immunocompromised critically ill: A systematic review and meta-analysis, Respir Care. 2018;63 (12):1555-1566

67. Azoulay E, Lemiale V, Mokart D et al. Effect of highflow nasal oxygen vs. standard oxygen on 28-day mortality in immunocompromised patients with acute respiratory failure. JAMA 2018; (Epub ahead of print) October 24, 2018.

68. Frat JP, Ragot S, Girault C, Perbet S, Prat G, Boulain T, Demoule A, Ricard JD, Coudroy R, Robert R, Mercat A. Effect of non-invasive oxygenation strategies in immunocompromised patients with severe acute respiratory failure: a post-hoc analysis of a randomised trial. The Lancet Respiratory Medicine. 2016 Aug 1;4 (8):646-52. 